\title{
Evaluation of Biofilm Formation in Staphylococcus aureus Clinical Isolates
}

\author{
Abolfazl Khandandel (PhD \\ candidate) \\ Department of Microbiology, \\ Ayatollah Amoli Branch, Islamic Azad \\ University, Amol, Iran \\ Hami Kaboosi (PhD) \\ Department of Microbiology, \\ Ayatollah Amoli Branch, Islamic Azad \\ University, Amol, Iran \\ Ailar Jamalli (PhD) \\ Laboratory Sciences Research Center, \\ Golestan University of Medical \\ Sciences, Gorgan, Iran \\ Fatemeh Peyravii Ghadikolaii (PhD) \\ Department of Biology, Ghaemshahr \\ Branch, Islamic Azad University, \\ Ghaemshahr, Iran \\ Corresponding author: Hami \\ Kaboosi \\ Tel: +98-9125722900 \\ Email: hkaboosi@gmail.com \\ Address: Department of \\ Microbiology, Ayatollah Amoli \\ Branch, Islamic Azad University, \\ Amol, Iran \\ Received: 12 Dec 2018 \\ Revised: 07 Jan 2019 \\ Accepted: 25 Jan 2019 \\ (c) (7) \& \\ This work is licensed under a Creative \\ Commons Attribution 4.0 License.
}

\begin{abstract}
Background and Objectives: Staphylococcus aureus is a common cause of nosocomial infections. The ability of $S$. aureus to form biofilm and acquire antimicrobial resistance has made this organism a major health problem. In this study, we investigate the biofilm-forming ability of $S$. aureus isolates from clinical samples.

Methods: Sixty $S$. aureus isolates from clinical specimens were collected from the 5th Azar Hospital of Gorgan (Iran) in 2018. The isolates were identified using conventional methods including Gram staining and biochemical tests (catalase and coagulase). Biofilm formation by $S$. aureus isolates was evaluated using a microplate-based method.

Results: $0 \mathrm{f} 60 \mathrm{~S}$. aureus isolates, $47(78.3 \%)$ strains were identified as biofilmforming and $13(21.7 \%)$ strains were non-biofilm-forming.

Conclusion: The high prevalence of biofilm-producing $S$. aureus isolates in the $5^{\text {th }}$ Azar hospital of Gorgan could pose a major health challenge with serious consequences for hospitalized patients. Therefore, it is crucial to disinfect and sterilize hospital surfaces and equipment effectively to minimize the risk of contamination and spread of bacteria in the hospital settings.

Keywords: Biofilms, Staphylococcus aureus, sample.
\end{abstract}

This paper should be cited as: Khandandel A, Kaboosi $H$, Jamalli A, Peyravii Ghadikolaii $F$ [Evaluation of Biofilm Formation in Staphylococcus aureus Clinical Isolates]. mljgoums. 2019; 13(4):14-16 


\section{INTRODUCTION}

Hospital infections are a global health problem associated with a variety of factors. Since the 1980s, Gram-positive bacteria, especially Staphylococcus aureus, have been considered as the main cause of hospital infections (1). The ability of $S$. aureus to form biofilm and acquire antimicrobial resistance has made this organism a major health problem (2). The bacterium causes a variety of infections, including bacteremia, septicemia, pneumonia, as well as skin, soft tissue and bone infections (3-4). These bacteria are catalase-positive, non-spore forming and often lack capsule. They can grow in different environmental conditions and are the second most common cause of nosocomial infections (5).

Biofilm formation is associated with increased resistance to antibiotics and host defense system (6). Bacteria within the biofilm are surrounded by extracellular polymeric substances (7). Given the importance of $S$. aureus infections in hospitals and the associated risk of mortality (8), we aimed to study biofilm formation ability in $S$. aureus isolates from clinical specimens.

\section{MATERIALS AND METHODS}

The study was carried out on $60 \mathrm{~S}$. aureus clinical isolates that were collected from the $5^{\text {th }}$ Azar Hospital of Gorgan (Iran) in 2018. The isolates were identified using conventional methods such as Gram staining, biochemical tests (catalase and coagulase) and mannitol fermentation or DNase test if necessary (9). The biofilm-forming ability of $S$. aureus isolates was studied using a microtiter plate based crystal violet assay. First, 24-hour culture of each bacterial isolate was inoculated into Mueller-Hinton agar and Tryptic soy broth containing $1 \%$ glucose. After incubation at $37^{\circ} \mathrm{C}$ and obtaining a turbidity equivalent to the McFarland 0.5 standard (or 0.1-0.8\% absorbance at $570 \mathrm{~nm}), 200 \mu \mathrm{l}$ of bacterial suspension were inoculated into wells of a polystyrene 96-well plate. Wells containing the medium alone were considered as negative controls. S. aureus ATCC 35556 was used as the positive control (10). To visualize biofilms, $200 \mu \mathrm{l}$ of crystalline violet $(2 \%)$ were added to each well. After five minutes, excess dye was discarded and the well was washed with $200 \mu \mathrm{l}$ of phosphate buffered saline (PBS) three times. The dye incorporated by the biofilmforming cells was dissolved by treatment with $200 \mu \mathrm{l}$ of ethanol-acetone (80: 20\%) for 30 minutes. Absorbance of each well at $570 \mathrm{~nm}$ was measured by an ELISA plate reader. A semi-quantitative study of biofilm formation was carried out using cut-off (OD570) values according to a method described previously $(11,12)$. The cut-off OD (ODc) was defined as three standard deviations above the mean OD of the negative control. All absorbance measurements were carried out in triplicate. Table 1 presents classification of the isolates in terms of biofilm formation based on the obtained ODc.

Table 1- Classification of the isolates in terms of biofilm-forming ability based on the microtiter-plate method

\begin{tabular}{ccc}
\hline Biofilm formation ability & Cut-off rate & Mean (maximum OD absorption) \\
\hline Strong & OD $>4 \times$ ODc 2 & OD $>1.2$ \\
Moderate & $2 \times$ ODc $<$ OD $\leq 4 \times$ OD & $0 / 7<$ OD $\leq 1.2$ \\
Weak & ODc $<$ OD $\leq 2 \times$ ODc & $0 / 3<$ OD $\leq 0.6$ \\
Non-biofilm-forming & OD $<$ cut off & OD $\leq 0.3$ \\
\hline
\end{tabular}

Cut off = mean OD of negative control $+(3 \times$ standard deviation of the negative control $)$

\section{RESULTS}

Of $60 \mathrm{~S}$. aureus isolates, $27(47 \%)$ were isolated from men and 33 (53\%) were isolated from women. In addition, $47(78.3 \%)$ strains were identified as biofilm-forming and 13 $(21.7 \%)$ strains were non-biofilm-forming. The biofilm-forming strains were isolated from urine $(n=12)$, blood $(n=5)$, cerebrospinal fluid $(n=8)$, wound $(n=17)$ and abscess $(n=5)$ specimens. Furthermore, $30(50 \%)$ isolates were strong biofilm producer and 17 (28.3\%) isolates were weak biofilm producer.

\section{DISCUSSION}

Biofilm acts as an important virulence factor for $S$. aureus by facilitating adhesion of the bacteria to various surfaces and increasing resistance to antimicrobial agents. Hence, infections caused by biofilm-forming $S$. aureus strains in hospitals are recognized as a major health challenge (13). The increased antibiotic resistance in these bacteria is mainly due to the presence of large quantity of extracellular polysaccharides in the biofilm that provides a favorable condition for the slow growth of 
bacteria (14). In our study, $78.3 \%$ of the isolates were identified as biofilm forming, which is alarming. In a study by Wang et al. (2012) in China, 66\% of the isolates were considered biofilm producers (15). In Ireland, the prevalence of biofilm-forming bacteria was $61.4 \%$ among clinical isolates (9). In Germany, $67 \%$ of isolates from blood samples and $47 \%$ of isolates from urinary tract infections were biofilm producers (8). In a study in the United States, $57 \%$ of the strains isolated from blood samples were able to adhere to polystyrene surfaces (16).

\section{CONCLUSION}

The high prevalence of biofilmproducing $S$. aureus isolates in the $5^{\text {th }}$ Azar hospital of Gorgan could pose a major health

\section{REFERENCES}

1. Ruiz A, Mora M, Zurita C, Larco D, Toapanta Y, Zurita Prevalence of methicillin-resistant Staphylococcus aureus among health care workers of intensive care units in Ecuador. J Infect Dev Ctries. 2014; 8(1): 116-9. doi: $10.3855 /$ jidc. 3535 .

2. Piette A, Verschraegen G. Role of coagulase-negative staphylococci in human disease. Vet Microbiol. 2009; 134(1-2):45-54. doi: 10.1016/j.vetmic.2008.09.009.

3. Secchi C, Antunes AL, Perez LR, Cantarelli VV, d'Azevedo PA. Identification and detection of methicillin resistance in non-epidermidis coagulase-negative staphylococci. Brazilian Journal of Infectious Diseases. 2008; 12(4): 316-20.

4. Afrough P, Pourmand MR, Zeinalinia N, Yousefi M, Abdossamadi Z, Yazdchi SB. Molecular Typing of clinical and Nasal Carriage Isolates of Staphylococcus auresus by spa Gene Patterns. J Mazandaran Univ med Sci 2016; 22(94): 28-34.

5. Francis A. Waldrogel. (Staphylococcus auresus). In: Mandell. Principles and practice of infectious Diseases. Gerald L.mandell, John E.Bennett, Raphael Dolin. $6^{\text {th }}$ ed. Churchill Livingstone: 2016; 2072-73.

6. Revdiwala S, Rajdev BM, Mulla S. Characterization of bacterial etologic agents of biofilm formation in medical devices in critical care setup. Crit Care Res Pract. 2012(2): 945805. DOI: 10.1155/2012/945805.

7. Bibalan MH, Shakeri F, Javid N, Ghaemi A, Ghaemi EA. Accessory gene regulator types of Staphylococcus aureus isolated in Gorgan, North of Iran. journal of clinical and Diagnostic Research. 2014; 8(4): 7-9.

8. Eftekhar F, Dadaei T. Biofilm formation and detection of icaAB genes in clinical isolates of methicillin resistant Staphylococcus aureus. Iranian Journal of basic medical sciences. 2011; 14(2):132-6. DOI: 10.22038/ijbms.2011.4978.

9. Croes S, Deurenberg RH, Boumans M-LL. Staphylococcus aureus biofilm formation at the physiologic glucose concentration depends on the $S$. aureus lineage. BMC microbiology. 2009; 9(1):1-2. challenge with serious consequences for hospitalized patients. Therefore, it is crucial to disinfect and sterilize hospital surfaces and equipment effectively to minimize the risk of contamination and spread of bacteria in the hospital settings.

\section{ACKNOWLEDGMENTS}

The study has been financially supported by the Infectious Disease and Medical Laboratory Sciences Research Center of the Golestan University of Medical Sciences, Iran (No: IR.GOUMS.REC.1397.116).

\section{CONFLICT OF INTEREST}

The authors declare that there is no conflict of interest regarding the publication of this article.

10. Wang R, Braughton KR, Kretschmer D, Bach T-HL, Queck SY, Li M, et al. Identification of novel cytolytic peptides as key virulence determinants for communityassociated MRSA. Nat Med. 2007; 13(12): 1510-4.

11. Rautenberg M, Joo HS, Otto M, Peschel A. Neutrophil responses tostaphylococcal pathogens and commensals via the formyl peptide receptor 2 relates to phenol-soluble modulin release and virulence. FASEB J. 2011; 25(4):1254-63. doi: 10.1096/fj.10-175208.

12. Cheung GY, Rigby K, Wang R, Queck SY, Braughton KR, Whitney AR, et al. Staphylococcus epidermidis strategies to avoidkilling by human neutrophils. PloS Pathog 6. 2010:e1001133.

13. Cucarella C, Tormo MA, Knecht E, Amorena B, Lasa I, Foster TJ, et al. Expression of the biofilmassociated protein interferes with host protein receptors of Staphylococcus aureus and alters the infective process. Infect Immun. 2014; 70(6): 3180-3186.

14. El-Feky MA,El-Rehewy MS, Hassan MA, Abolella HA, Abd El-Baky RM, Gad GF. Effect of ciprofloxacin and $\mathrm{N}$-acetylcysteine on bacterial adherence and biofilm formation on ureteral stent surfaces. Pol $\mathrm{j}$ Microbiol 2009; 58(3): 261-7.

15. Wang L, Yu F, Yang L,Li Q, Zeng XZ, Xu Y. Prevalence of virulence genes and biofilm formation among Staphylococcus aureus clinical isolates associated with lower respiratory infection. Afr $\mathrm{J}$ Microbiol Res. 2010; 4(23): 2566-9.

16. Namvar AE, Asghari B, Ezzatifar F, Azizi G, Lari AR. Detection of the intercellular adhesion gene cluster (ica) in clinical Staphylococcus aureus isolates. GMS hygiene and infection control. 2013; 8(1): Doc03. doi: 10.3205/dgkh000203. 